have small influence on the direct harm done (or pain given) by the criminal act; (2) to distinguish between what I have called the internal and external factors of temptation; (3) to distinguish between the pasition of a legialator and the position of a judge. With regard to this last distinction, it may seem strange that the same facto should be to one man a reason for increasing, to another a reason for decreasing punishment. But really the facts are not the same $A$ moralist who is deciding what ought to be done to a person who has actually done wrong has before bim facts which are on the Preventive Theory of much importance, but which are unknown to the moraliat who is laying down general rules for the future. It is just because these facts are of great importance that we think it well to leave the amount of punishment to be given in each case as a matter, within certain wide limite, for the judge's discretion.

F. W. MaItLayd.

DR BAIN ON PRER WILI,

In April, 1874-during the course of a philosophical saries with which I am still engaged in the Dublin Review - I came upon the question of Free Will. My direct assault was upon Mr. Stuart Mill and Dr. Bain, who are far the ablest advocates of Determiniam with whom I happen to be acquainted. Dr. Bain did me the honour of replying in the Third Edition of his very instructive work on The Emations and the Will. I rejoined in April and October of lest year, and he has rejoined on my rejoinder in the January number of Mirs.

In April last-while cordially acknowledging that Dr. Bain had treated me with most abundant courtesy - I was nevertheless obliged to complain that throughout his criticism he did not so much as once refer to that central and fundamental argument on which I avowedly brsed my whole case. Yet, as I added, nothing could well have been more express and emphatic than $m y$ detailed exposition of that argument. On the present occasion I must repeat the same acknowledgment and the same complaint. No one can write more handsomely of an opponent than he writes of me. He even says that "I have bestowed more attention on the controversy concerning Free Will, than any one with whom he is acquainted ". Moreover, the extracts he gives from my articles are evidently chosen with the view of exhibiting my position in the most fair and equitable light. And yet by some (as it were) fatality which I am quite unable to explain, he entirely ignores from first to last the precise point on which I lay stress. I have nothing left for it then, except to content myself with stating that point once more; nor shall I hesitate often to repeat the very words I have used in the Dublin Reviero. Indeed I shall be very glad to take this course; because my present audience is entirely different from that which I addressed in the Catholic periodical just named. On the other hand it is a considerable inconvenience to me that I am confined within somewhat narrow limits. It would have been unconscionable, however, to ask the Editor for a much longer space in defence than 
Dr. Bain has occupied in attack. And at last I shall not improbably have a future opportunity for supplying any defect which may be inovitable in my present Note.

I rill observe preliminarily, that Dr. Bain takes up far less confident ground than I had always understood Determinists to assume. I had always understood Determinists to allege, that their doctrine is certain and impregnably established. To this I answered (as Dr. Bain now quotes me) that " no Determinist with whom I happen to be acquainted had even so much as attempted to prove this," though so many have asserted it. Dr. Bain, after citing my statement, does not profess to deny it. He merely says that great presumption in favour of Determinism arises from the fact that "uniformity is found to be the rule of nature" in all unambiguous cases. His "present argument," he afterwerds adds, "merely requires that there should be a passiblo alternative to the supposition that the will is not subject to the law of aniformity. So long as there is no unequivocal instance on" my "side, such an explanation," he says, "deserves to be listenad to."

For the opposite doctrine, however, I claim, not probability, but certainty. I maintain that there are many " unequirocal instances" which conclusively disprove Determinism. Dr. Bain says that "if there be exceptions to the nniformity of nature, they ought ere now to have come into view in' some unmistakable cases." I reply that there are not " $80 \mathrm{me} \theta$ " only but very many "unmistakable cases," which peremptorily establish that certain actions of the human will are gignal and conspicuous "exceptions" to that "law of uniformity" which prevails generally in nature. And I proceed to place before my present readerg some of the arguments which I have elsewhere adduced in behalf of this conclusion.

Dr. Bain protests against the term "Free Will"; and " sees no chance of a reconciliation of the opposing views, until this term is abandoned." He ought then to look with more farour on my own controversial standpoint than on that of some other opponents; because-though I certainly cannot abandon the term "Free Will"still I have gone through the more esential and fundamental part of my reasoning, before I arrive at that term. I begin by merely maintaining a doctrine called by me "Indeterminism "; which is neither more nor less than the negative doctrine, that the doctrine of Determinism is untrue.

Now what is the doctrine of Determinism 9 Dr. Bain quotes with entire assent my own virtual exposition thereof. According to Deterministo-it holds quite universally that, "given certain physical and corporeal antecedente, one definite group of physical consequents infallibly and inevitably ensue". This is what Indeterminists deny, as regards certain movements of the human will. In order, however, more conveniently to discuss the question, let me take a particular case. Let me suppose that at some given moment tro mutually different courses of action are open to you, and that you have to choose between them. Let me further put aside the more common case, that. there is a complication of motives soliciting you on one side or on 
both Lat me suppose that there is one strong motive attracting you in one direction and another in the other, while all other motives on either side are 80 comparatively weak that they may be left ont of account. ${ }^{1}$ I will first confine myself to such a particular case as this; becanse all controversalists will admit, that it is especially fitted for bringing the question to a definite issue.

Such a case then being supposed, Dr. Bain considers it to be experientially known which of these two motives is "the stronger," by the very fact that it carries the day. "Two powers are in conflict, and the result shows their relative force" The saccessful motive " exercises control, not by freedom of the will, but by the psychological power of the stronger". If antecedents were to recar in every respect precisely similar, the result would infallibly and inevitably be the eame. According to Deterministe, that motive which under present circumstances is the stronger, under precisely. similar circumstances would again be the stronger. Moreover, according to Determinista, the stronger motive infallibly and inevitably prevails over the weaker. I am confident that all Determinists will endorse this statement of their thesis as undeniably fair and accurate. And it is against their thesis as so stated, that my reasoning has been directed.

Now many Libertarians deny that there is any intelligible sense in the afflrmation, that one motive is "stronger" than another. For my own part, however, I submit that there may be a most intelligible meaning in the affirmation; and that the term, if 80 onderstood, is a very serviceable one. So far I am in agreement with Dr. Bain I differ from him, however, in the ense which I give to this term. When he says that at this moment motive $\Delta$ is "Btronger" with you than motive B,- - he merely means that as a matter of fact you give preference in action to the former over the latter. But when on my side I say that motive $A$ is "stronger" at this moment with you than motive B,-I mean that the opontaneous impulse - the direct tendencyof your will at this moment is towards acting on the former in preference to the latter. According to my terminology, then, it is not the will's qetion, but its spontaneous impulse, which evinces the relative "strength" of motives. And then, as an Indeterminist, I proceed to maintain a second proposition-viz, that by no means unfrequently you act in opposition to your spontaneous impulse, to your strongest motive. The first of my two propositions, it will be seen, is purely verbal; but the second is most substantial And I will proceed at once to adduce various correlated practical instances to illustrate both these propositions. I will follow Dr. Bain's precedent, and take my examples from the sports of the field.

I In my articles I have distinguished between two different ideas which are commonly expressed by this word "motive". And I think indeed that this distinction is of much importance in the exparition of what I account sound doctrine. But in anguing with an opponent, it may be more convenient to waive this distinction. Here, therefore, I will use the word "motive" to express any thought which in any way prompts the will to act in any given direction. 
A long frost has at last broken up, and you are looking forward with keenest hope to your day's hunting. Your post, however, comes in early; and you receive a letter just as you have donned your red coat and are sitting down to breakfest. This letter announces that yon must eet off on this very morning for London, if you are to be present at gome occasion on which your presence will be vitally impartant, for an end which you ecount of extreme public moment. Lat me consider the different ways in which your conduct may imaginably be affected, and the light thus thrown on the relative strength of your motives.

Perhaps (1) the public end, for which your presenco is so urgently needed, happens to be one in which you are so keenly interested, which so intimately affects your feelings that your balance of emotion is intensely in favour of your going. This motive, then, is indefinitely "stronger" than its antagonist. You at once order your carriage, as the railway station is some fonr miles off; and you are delighted to start as soon as your carriage comes round. Perhaps (2) the balance of your emotion on the contrary is quite decidedly in favour of the day's hunting: because the public end-though intellectually you appreciate its exceptional importance-is not one with which your character leads you emotionally to aympathise. Nevertheless, through a long course of public-spirited action, and through "stored up memories of the past"-you have acquired the habit of postponing pleasure to the call of duty. Here, therefore, just as in the former case, there is not a moment's vacillation or hesitation : your spontaneours impulse is quite urgently in favour of going. Your balance of emotiom, I repeat, is in favour of staying in the country to hunt. But good habit by its intrinsic etrength spontaneously prevails orer emotion; and (taking your natare and circumstances as a whole) the motive which prompts you to go is indefinitely stronger than that which prompts you to stay. Or (3) perhaps, when you have read the letter, your will is brought into a state of vacillation and vibration. Your emotional impulse is one moment in one direction, and the next moment in another. Then-as you possess no firm habit of pablic spirit-you take a long time in making up your mind. As Dr. Bain would say -and as I equally should say-the strength of your motives is very evenly balanced, whichever may happen finally to show itself stably the stronger. Lastly (4) you have perheps very little public spirit, and are passionataly fond of hunting. So you at once togs your letter into the fire: and do not even entertain the question whether you shall offer op your day's sport as a sacrifice to your country's welfare. In this case of course the motive which prompts you to stay is indefinitely stronger than that which prompte you to go.

Now all these four alternatives are contemplated by the Determinist, and square most essily with his theory. In each case your conduct is determined by your strongest present motive. But there is a fifth case which he does not-and consistently with his theory cannotadmit to be a possible one; but in regard to which I confidently main- 
tain, by appeal to experience, that it is abundantly poseible, and by no means indeed unfrequent. It is most possible, I say, that you put forth on the occasion what I have called in my articles " anti-impulsive effort "; that you act resolutely and consistently in opposition to your spontaneous impulse; in opposition to that which at the moment is your strongest motive. Thus-On one side the sponteneous impulse of your will is quite decidedly in favour of staying to hant; and the motive therefore which prompte you to do 80 is quite decidedly stronger at the moment, than that which would draw you to London. On the other hand your reason recognises clearly how very important is the public interest at issue, and how plainly duty calls you in the latter direction. You clench your teeth, therefore, and resolutely set yourself to resist the spontaneous impulse of your will. You resolutely doff your hunting dress; you resolutely order your carrisge which shall take you to the station; you resolutely enter it when it comes round. And now let me follow your course during the four miles' transit which ensues During the greater part-perhape doring the whole - of this transit, thero procesds what $I$ have called in my articles "a componnd phenomenon"; or, in other words, there co-exist in your mind two mutually distinct phenomene First phenomenon. Your will's preponderating spontaneous impulse is stably set in one given direction. You remember that even now it is by no means too late to be present at the meet; you are restless and ill at ense; you are most urgently solicited by inclination to order your coachman home again So urgent, indeed, is this solicitation- $-\infty$ much stronger is the motive which prompte you to return than that which prompte you to continue your courso-that, unless you exercised unintermitting selfresistance, self-government, self-control, you would quite infallibly give the coachman such an order. Here is the first phenomenon to which I call attention: your will's spontaneous impulso towards roturning. A second, no less distinctly pronounced and strongly marked, phenomenon is that unintermitting self-resistance, self-government, celf-control, of which I have been speaking. On one side is that phenomenon, which I call your will's predominant epontanenus impulse or desire; on the other side that which I call your firm and sustained antagonistic resolve. On one side is the strongest motive, the spontaneous impulse, the predominant desire; on the other side is that which I call anti-impulsive effort and effectual resolve.

Here, then, I come to the point of my argument. How has this spontaneous impulse or desire been generated i Dr. Bain must surely answer this question as I do. $\mathrm{He}$ must say that your spontaneous impulse of the moment is the inevitable and infallible outcome of your circumstances (external and internal) as they exist at this moment. What other account of ite genesis could possibly be given? We may know then quite certainly what is the resultant at this moment of the motives which solicit your will, by knowing what is the spontaneous impules of your will at this moment. $Y$ et in such a case as I have supposed, it is a plain matter of fact, that you are not acting in accordance with your spontaneous impulse. Or (in other words) it is a plain 
matter of fact, that you are not doing that to which your circumstances of the moment dispose you. But Determinists eay that you must alioays infallibly and inevitebly do that to which your circumstances of the moment. dispose you. Therefore Determinists are fundamentally mistaken

It is this "compound phenomenon," as I have called it-the like of which are surely very far from unfrequent-on which I have throughout mainly rested my argument. And I have now described it almoet in the very words used by me last October. Dr. Bain saye that the phenomenon which I describe "is no new phenomenon in human experience," and so far of course I am zealonsly at one with him. But he adds that this phenomenon "is spoken of in every acconnt of the constitution of the mind". Now Dr. Bain has himself written a most able "account of the constitution of the mind". I have read with great attention, and (I'hope) with great instruction, that portion of his labours which treats " the Emotions and the Will". But I protest that I cannot find in any part of that volume any recognition whatever of such facts as that on which I have been laying streas. It would interest me extremely if he, or some one of his many eympathisers, would refer me to the page-ray in the Third Editionwhere I shall find such facts (1) recognised, and (2) explained in some way different from mine.

At this stage of my argumeut, I proceed from the general doctrine of Indeterminism to the special doctrine of Free Will. Once more I beg my readers' attention to those two phenomena on which I lay gtress. I draw attention to them as they co-exist, e.g., in the country gentleman, who has left his day's hunting very moch against the grain, from a motive of public duty, and who is in his carriage en route to the station. On one side is his greatly preponderating epontaneous impulse towards returning; on the other is anti-impulgive effort, succesafully contending againgt that impulse. If we examine these two phenomena successively with due care, we shall see that they differ from each other in character not less than fundamentally. In experiencing the former of them, his will has been entirely pessive: in eliciting the latter, it is intensely active. $\mathrm{He}$ is not only conscious (I say) that he elicits this act of resistance : he is no one whit less directly conscious, that he elicits it by his oun active exertion No doubt motives differ from each other indefinitely as regards their relative "strength"; that is, as regards the influence which they respectively exercise on the will's spontaneous impulse or passive tendency. Still the agent is not left at their morcy, if I may so express myself. His will possesses intrinsic strength of its own, whereby on occasion it can choose to act on a motive which is for the moment weaker, rather than on one which is for the moment stronger. This fact, I say, is impressed most unmistakably on his knowledge, by such an experience as I have described. His soul-such is the fact which he recognises-has on certain occasions the power of redressing the balance of motives, by throwing its own self-originated force ${ }^{1}$ into this or that scale. And this is precisely an exercise of Freo Will.

${ }^{2}$ Let no Theist misanderstand this term "self-originated" force. I ex$18 \star$ 
Hitherto I have so spoken as to embrace those instances only, in which (1) no more than two alternatives are presented; and in which (2) only one motive for either alternative needs to be considered. But I can easily express my argument in a much more general form. I can so express it as to include those far more frequent cases, in which (1) there are various courses of action from which a choice may be made; and in which (2) multifarious motives are at work, soliciting the agent in several different directions. Far oftener than not, he can know with absolnte certainty what is the exact resultant of these various motives; what is the exact direction in which their combined influence solicits him. He can know this at once, I say, with certainty ; because he can recognise quite unmistaksbly what at the moment is his will's spontaneous impulse or desiro-its passive tendency. This spontaneous impulse or pasqive tendency messures of course with infallible accuracy the preponderating influence exercised over his mind, by that complex of motives which for the moment is combinedly at work. But he knows also by actual experience, that on certain occasions he pute forth a vigorous self-originated effort, whereby he compels himself to act in some way entirely different from that prompted by his will's spontaneous impulse and passive tendency. On such occasions then he knows by experience that he compels himself, by a self-originated and vigorous effort, to act in some way entirely different from that, towards which his balance of motives at the moment prompts him. But Determinists will be the first to admit, that such self-originated resistance to the balance of motives-if it existed-would be an exercise of Free Will.

I am greatly disappointed that my limits do not permit me to continue further the exposition of my argument, as it is contained in the Dublin Revieto. In particular, $I$ should have wished to illustrate in some detail the braad phenomenal contrast which exista between two classes of acts, which I have called respectively acts of " anti-impulsive" and " congenial" efforts. By " effort" I meant "resistance to desire". By "congenial effort" I mean "resistance to some (at the moment) weaker desire or weaker motive; in order to the gratification of some (at the moment) stronger desire or stronger motive". By "antiimpulsive" effort I mean " resistance offered by self-originated exertion of the will to what (at the moment) is the agent's strongest desire or motive". Now, Determinists hold that a weaker desire indeed will be overcome by a stronger; but they add that the strongest present desire cannot possibly be overcome by the will's self-originated resolve. They must maintain therefore, of course, that no such acts are possible as those of "anti-impulsive" effort. They maintain that all effort of the will is really what I call "congenial," and consiste merely in crushing a weaker desire under influence of a stronger. I have argued in the Dublin Reviow that this affirmation is in direct contradiction to manifest mental facts; that what I call "anti-impulsive efforts" present the

plained clearly last April the sense in which a Theist may mast consistently use it. 
broadest possible phenomenal contrast to those efforts which I call " congenial". But I could not do any hind of justice to this argument unless I exhibited various individual illustrations of $\mathrm{my}$ statement. And for this I have here no room.

As I have already implied, Dr. Bain really offers no reply whatever to the argament I have now set forth. He does not even exhibit it, much less reply to it. The nearest approach I can find to any rocognition of it, is his reference to "stored up memories of the past" 8 influencing human action. No doubt they do so most importantly. But in what manner do tbey influence it $\mathrm{Dr}$. Bain himself must reply, by modifying the will's spontaneors impulos; by effecting that such impulse shall be in this direction rather than in that Yet if this be so, how can these "stored up memories" tend ever so remotely to account for a man resisting his spontaneong impalse? I am here but repeasing what has been said by an able and most kind critic in the spectator of Jan. 10th. But I must add that the fact of Dr. Bain suggesting such an answer is the best of all possible proofs, how little he has given his mind to the point of my argament.

What he has really done is-not to answer my reasoning at allbut to allege various objections against the conclusion to which my angument pointa. These I will now briefly consider.

1. He complains "that he cannot grasp clearly what Freo Will means". Well-I answered this question at some little length last April, and Dr. Bain has not yet explained which of my statements are to him unintelligible. Here, howerer, I may. briefly gire an answar which I think is substantially accurate, founded on my preceding remarks in this Note. If an agent at any given moment has a real power of successfully resisting his will's spontaneous impulse and paseive tendency, -at such moment his will is free. If he exercises the said power, he exercises Free Will. Nay, if he refuecs to exercise it-nevertheles his will may at the moment be free; because he can exercise this power if he chooses, and he has foll power (within cortain limits) 80 to choose.

2. Dr. Bain "wonld like to have the region of failure of uniformity closely circumscribed". In other words (as I understend him) he wishes to know how often in the day, on what occasions, under what conditions, I maintain that a man's will is free. I briefly entered on this enbject at the end of my article of last April, and expressed a hope of treating it fully hereafter. I fancy that Libertarians would considerably differ from each other in their answer to this question; which, however, has really no bearing on the essential point at issue between Theists and Antitheists. My own humble view is, that a man's will is free during pretty nearly the whole of his waking life.

3. Dr. Bain implies a wish to understand how such a science as peychology can possibly exist, if so many poychical phenomena are external to the ephere of uniform phenomenal sequence. I admit heartily that this is an inquiry which Libertarians are bound expresaly and intelligibly to confront. For my own part I did confront it, in an article on "Science, Prayer, Froe Will, and Miracles," published by mo 
in the Dublin Reviewo as far back as 1867. I shall have great pleasuro in forwarding Dr، Bain a copy of that article. At the same time it may be as well here to point out one obvious fact. The "sponteneous impulse" or "passive tondency" of any given man's will, at any giren. moment, is a matter open to scientifio calculation in the strictest senee. This particular phenomenon at all erents is infallibly and inevitably determined by.phenomenal antecedente. In fact (as I said last October). I think that paychologians have been unduly remiss in not labouring more actively towards the exploration of this phenomenon. Consider -as one instance out of many-the mutual ralations of emotion and habit. Under what circumstances does emotion sponteneously prevail over habit 9 Conversely, under what circumstances does habit spontaneously prevail over emotion 1 How very little has jet been dono (so far as I happen to be amare) towards elucidating this question!

4. Dr. Bain especially deaires to know, how Libertarians stand with regard to the doctrine of causction He asks, e.g., whether, according to Libertarians, "from the accurrence of a given antecedent, we can conclude what the consequent will ben. Surely he must be well aware, that every Libertarian answers this question emphatically in the negative. In any given instance of free action, the elicited act of will is not infallibly determined by its phenomenal antecedents, but on the contrary is elicited by the agent according to his own unfettered choice. This is just what we mean when we say that the action is free.

"Can there then be such a phenomenon"-Determinista ask-" as a car seless volition q" In my article of last April I trested this matter in detail. The difficulty raised I understand to bo this, though I am expressing it in my own words. "It. is a truth accepted by the common sense of mankind, that every event has a cause. In fact this ls the very truth which we call the 'doctrine of causation'. But by a 'cause' is meant a' phenomenal antecedent, from which the 'effect' engues in the way of uniform phenomenal sequence. Now there are certain acts of the will, in regard to which Libertarians deny that such acts do proceed from phenomenal antecedents in the way of uniform phenomenal sequence. Therefore Libertarians deny that "doctrine of causation,' which is accepted by the common sense of mankind."

It has always amazed me that Determinists can 800 any force in this objection. I am the last to deny that many of their arguments are extremely plansible, and demand most careful consideration. But this particular argument has its origin in a perfectly. marvellous confusion of thought. Intuitionists entirely deny-as is surely quite notorious - that the word 'canse' has (in the accepted doctrine of causation) the sense which a Determinist supposes. They entirely deny that the common sense of mankind accepts the 'doctrine of cansation' in the sense in which a Determinist understands it. They entirely deny that in that sense the doctrine is true. They confidently affirm that in that sense the doctrine is false. Yet eren so unusually able and thonghtful a writer as Mr. Leslie Stephen, has fallen a victim to the fallacy of which I am epeaking. He represents Libertarian Theists as holding that " we are bound by a necessary law of thought to believe in uni- 
versel causation"; and so far he represents them truly. But he proceeds to represent them as "saying that another necessary law of thought tells us that causation is not nniversal," because that man's will is free. ${ }^{1}$ On the contrary, Libertarians are removed in the furthest possible degree from admitting that a free human act involves a "causeless volition". They say that such an act exemplifies the doctrine of causation more expressly, more emphatically, more clamourously, than does any other phenomenon in the world. All this I set forth to the best of my power last April; and Dr. Bain-eccording to his wont-has referred to my argument without attempting to answer it.

5. At last, I think that Dr. Bain lays his chief strese on the fact, that all other phenomena proceed by aniformity of sequence. $\mathrm{He}$ regards it as in the very highest degree improbable that one particular class of phenomena-viz, haman volitions - should be an exception to this otherwise universal rule. But he makes no way whatever in controversy, by merely pointing out that according to his oton theory of life, such exceptionality is most improbable: he has to show (if he can) that it is improbable according to his opponent's theory of life. Now, according to his opponent's theory of life, such an exceptionality is not only not an improbability, it is an absolnte necessity. There can be no such thing as Theistic morality without Free Will On the other hand, if you deny Theistic morality-then (I quite admit) Free Will would be en uncouth, unmeaning, portentous exception to the otherwise universal course of nature. In fact, I may turn the tables on Dr. Bain. Unless Theistic morality be sound doctrine, Free Will is a portentons and unintelligible anomaly. But (as I I truat I have shown) Free Will indubitably exists Dr. Bain, therefore, either must admit that there exists what he himself would describe as a portentous and unintelligible anomaly, or else he must admit that Theistic morality is sound doctrine.

W. G. W

\section{VII.-CRITICAL NOTICES.}

An Inquiry into the Process of Human Experience: attempting to set forth its lower Lavos, with some hints as to the higher Phenomona of Conseiousness. By Writsur CrPLes. London: Strahan \& Co., 1880. Pp. 806 .

As the title suggests, this voluminous work aims at supplying a complete scheme of philosophical doctrine. Beginning with an account of the facte of empirical paychology as studied and observed in the light of recent phyeiological research, the writer gradually advances to the discussion of the questions of the vltimate nature of Conscionsness, the existence of a soul or spiritual entity, the relation of the phenomena of the higher moral consciousness to religious doctrine, together with the more practical problems of philosophy such as the

1 Fortnightly Revicw, Jano 1876, p. 818, "An Agnastic's Apologp", 